\title{
Thin Layer Chromatography Fingerprinting and Clustering of Orthosiphon stamineus Benth. from Different Origins
}

\author{
Kartini Kartini ${ }^{1, *}$, Ervina Rustiana Dewi ${ }^{1}$, Fandi Achmad', Nikmatul Ikhrom Eka Jayani', Mochammad Arbi \\ Hadiyat $^{2}$, Christina Avanti ${ }^{3}$
}

Kartini Kartini ${ }^{1, *}$, Ervina Rustiana Dewi', Fandi Achmad', Nikmatul Ikhrom Eka Jayani', Mochammad Arbi Hadiyat $^{2}$, Christina Avanti ${ }^{3}$

'Department of Pharmaceutical Biology, Faculty of Pharmacy, University of Surabaya, Raya Kalirungkut Road, Surabaya 60293, INDONESIA.

${ }^{2}$ Department of Industrial Engineering Faculty of Engineering, University of Surabaya, Raya Kalirungkut Road, Surabaya 60293, INDONESIA.

${ }^{3}$ Department of Pharmaceutic, Faculty of Pharmacy, University of Surabaya, Raya Kalirungkut Road, Surabaya 60293, INDONESIA.

\section{Correspondence}

\section{Kartini Kartini}

Department of Pharmaceutical Biology,

Faculty of Pharmacy, University of

Surabaya, Raya Kalirungkut Road, Surabaya 60293, INDONESIA

E-mail: kartini@staff.ubaya.ac.id

History

- Submission Date: 14-11-2019;

- Review completed: 29-11-2019;

- Accepted Date: 09-12-2019.

DOI : 10.5530/pj.2020.12.13

Article Available online

http://www.phcogj.com/v12/i1

\section{Copyright}

(C)2020 Phcogi.Com. This is an openaccess article distributed under the terms of the Creative Commons Attribution 4.0 International license.

\section{ABSTRACT}

Introduction: Orthosiphon stamineus has been widely used across Asian countries for the treatment of various diseases. The quality of herbal medicine determine its safety as well as efficacy; and geographical origin is important factor contributing on the quality of herb and its products. Materials and Methods: Thin Layer Chromatography (TLC) method combined with chemometric, Principal Component Analysis (PCA), has been employed to evaluate the quality of Orthosiphon stamineus leaves collected from eleven origins in Indonesia. Results: The results showed that mobile phase suitable for Orthosiphon stamineus was chloroform, dichloromethane, ethyl acetate $(7: 4: 1)$. The method used has met the requirements of TLC system stability and precision. TLC-fingerprints analyzed with chemometrics showed an ability to discriminate Orthosiphon stamineus from various origins. PCA score plot of the first two principal components (PC) clearly distinguished 3 clusters of samples, whereas the loading plot of the first two PC showed that compounds with the Rf values of $0.0-0.1,0.1-0.2,0.2-0.3$, and 0.9-1.0 are the most important compounds for clustering of samples. Conclusions: TLCfingerprint combined with the PCA was able to discriminate among the leaves of Orthosiphon stamineus originated from various locations. TLC-fingerprints analyzed with chemometrics can be used as an alternative of marker-oriented method to evaluate the quality of Orthosiphon stamineus.

Key words: Geographical origin; Herbal medicine; Marker; Principal component analysis; Quality; TLC.

\section{INTRODUCTION}

Orthosiphon stamineus (Indonesia: Kumis kucing) is a member of the Lamiaceae family. This plant has been empirically used in several Southeast Asian countries, such as Indonesia, Malaysia, Thailand, Vietnam, and Myanmar. Orthosiphon stamineus (OS) in Indonesia is traditionally used for diuretic, rheumatic, diabetes, hypertension, tonsillitis, epilepsy, menstrual disorders, gonorrhea, syphilis, kidney stones, nephritis, gout arthritis, and antipyretics. ${ }^{1}$ Various studies on OS and its compounds indicated that this plant has antioxidant, cytotoxic, diuretic, nephroprotective, antidiabetic, antihypertensive, anti-inflammatory, antimicrobial, anti-obesity, and hepatoprotective activities, as well as activity on the cardiovascular system..$^{1-5}$ Bioactivities of OS has been attributed by its various chemical constituents classified as monoterpenes, diterpenes, triterpenes, essential oil, sterols, saponins, flavonoids, and organic acids. ${ }^{1,6}$

Orthosiphon stamineus is an herbaceous plant and it has two types of flower, white and purple colour. This variety may cause the differences in chemical contents as well as biological activities. ${ }^{7}$ The purple variety has more bioactive compounds than the white one. However, most scientific investigations have used the white variety. ${ }^{8}$ Moreover, solvent, duration, temperature, and method of extraction as well as geographical location may also influence the chemical compounds of OS. ${ }^{6,9-13}$ Geographical origin of plants is important to be recognized since it affects the levels of bioactive compounds, a general criterion in the selection of raw materials. Therefore, a simple and accurate analytical method is needed to identify the geographical origin of OS.

Quality evaluation of OS crude drugs and its extract can be carried out using two approaches, the concentration of marker compound(s) and the profile of fingerprint. A groups of marker, rosmarinic acid (RA), 3'-hydroxy-5,6,7,4'-tetramethoxyflavone (TMF), sinensetin (SIN), and eupatorin (EUP) have been determined using HPLC ${ }^{11}$ and HPTLC ${ }^{13,14}$ methods to evaluate OS extract obtained from various origins, solvent, and method of extraction. Gas chromatography (GC) and FT-IR have been applied to develop the fingerprint of OS collected from various origins and prepared with different methods of extraction. ${ }^{7,10-12}$

Application of fingerprint reveals several superiorities compared to those of marker compounds. Fingerprint is a distinctive profile or pattern of sample which chemically reflects its composition in which as much information as possible is presented. ${ }^{15,16}$ Therefore, almost all of compounds in a plant are considered in the analysis. This allows quality evaluation of a plant to be more objective than using only certain compound(s). TLC-fingerprint has been widely used in herbal medicines assessment. It is simpler, faster, and more cost effective compared to GC, 
HPLC, and FT-IR. TLC is able to analyze many samples in one running time. It is also possible to visually analyze TLC-chromatograms; however, this technique is subjective and not quantitative. Moreover, fingerprint chromatograms are complex multivariate data sets which cause difficulty in evaluation of very similar chromatograms. Thus, chemometrics should be taken into consideration. This approach, although more difficult, is based on objective mathematical methods and treats the chromatogram as a unique signal, without a need to identify and interpret the peaks. Therefore, it provides a good possibility for mining more useful chemical information from originalrich data. ${ }^{16-18}$ In this research we developed TLC-fingerprint combined with chemometrics to differentiate OS collected from various origins. Although several works on fingerprinting of OS have been reported before, none of them involved comparison between OS from different origins using TLC method.

\section{MATERIALS AND METHODS}

\section{Chemicals}

The following chemicals were procured from Merck (Darmstadt, Germany): TLC plate pre-coated with silica gel $60 \mathrm{~F}_{254}, \mathrm{n}$-hexane, diethyl ether, tetrahydrofuran, acetic acid, n-propanol, dichloromethane (DCM), ethyl acetate (EA), dioxane, toluene, chloroform $\left(\mathrm{CHCl}_{3}\right)$, methanol, ethanol, anisaldehyde, and sulfuric acid.

\section{Plant materials}

Orthosiphon stamineus were collected from eleven cultivation area in East and Central of Java, Indonesia (Table 1, Figure 1). Plant parts used were 5 leaves from the shoots that have not flowered yet. Leaves were harvested and cleaned with tap water. All samples were authenticated by Center for Traditional Medicine Information and Development, Faculty of Pharmacy, University of Surabaya, Indonesia (certificate number: 1400/D.T/V/2019). Leaves were then dried and ground into mesh 60.

\section{Preparation of extracts}

One gram of powdered Orthosiphon stamineus leaves was extracted with $10 \mathrm{ml}$ of methanol, using Ultrasound-Assisted Extraction (UAE) method for 15 minutes. Extracts were subsequently filtered and kept in a tightly closed bottle.

\section{TLC-fingerprint analysis}

\section{$T L C$ condition}

A Camag TLC system comprising of Linomat 5 sample applicator, twin-through chamber, and TLC-Visualizer with 12 bit CCD camera and Camag VideoScan 1.02 software serial number 2503D001 (Camag, Muttenz, Switzerland) were used. Chromatography was performed on Merck TLC plates (Art. No.: 1.05554.0001, silica gel $60 \mathrm{~F}_{254}$ pre-coated, $20 \times 20 \mathrm{~cm}, 175-225 \mu \mathrm{m}$ layer thickness, aluminium-backed, particle size distribution: 9.5-11.5 $\mu \mathrm{m}$ ) with a $100-\mu \mathrm{l}$ Camag syringe. Samples were spotted under a flow of nitrogen as $8 \mathrm{~mm}$ bands, $10 \mathrm{~mm}$ from the left edge, $15 \mathrm{~mm}$ from the bottom edge and $20 \mathrm{~mm}$ of track distance. Development was carried out in a chamber previously equilibrated (for $30 \mathrm{~min}$ at room temperature) with mobile phase (see: selection of mobile phase) and migration distance was $80 \mathrm{~mm}$. The plates were dried under room temperature and then dipped in anisaldehyde-sulfuric acid reagent. TLC plates were then dried in fume hood and heated for 10 min at $100^{\circ} \mathrm{C}$. TLC plate were subsequently illuminated under shortwave UV ( $254 \mathrm{~nm})$, long-wave UV (366 nm), and white light by using

Table 1: Geographical origins of Orthosiphon stamineus from Indonesia.

\begin{tabular}{|c|c|c|c|c|}
\hline Code & District (City) & Height (mamsl)* & Latitude, Longitude & Time of collection \\
\hline $\mathrm{A}$ & Lamongan & 6 & $7^{\circ} 11^{\prime} \mathrm{S} ; 112^{\circ} 42^{\prime} \mathrm{E}$ & May 2019 \\
\hline B & Pasuruan & 800 & $7^{\circ} 41^{\prime} \mathrm{S} ; 112^{\circ} 39^{\prime} \mathrm{E}$ & May 2019 \\
\hline $\mathrm{C}$ & Malang & 445 & $7^{\circ} 43^{\prime} \mathrm{S} ; 112^{\circ} 40^{\prime} \mathrm{E}$ & May 2019 \\
\hline $\mathrm{D}$ & Gresik & 3 & $7^{\circ} 10^{\prime} \mathrm{S} ; 112^{\circ} 40^{\prime} \mathrm{E}$ & May 2019 \\
\hline E & Surabaya & 2 & $7^{\circ} 15^{\prime} \mathrm{S} ; 112^{\circ} 42^{\prime} \mathrm{E}$ & May 2019 \\
\hline F & Sidoarjo & 3 & $7^{\circ} 29^{\prime} \mathrm{S} ; 112^{\circ} 43^{\prime} \mathrm{E}$ & May 2019 \\
\hline G & Jombang & 44 & $7^{\circ} 20^{\prime} \mathrm{S} ; 112^{\circ} 45^{\prime} \mathrm{E}$ & May 2019 \\
\hline $\mathrm{H}$ & Mojokerto 1 & 700 & $7^{\circ} 40^{\prime} \mathrm{S} ; 112^{\circ} 36^{\prime} \mathrm{E}$ & May 2019 \\
\hline I & Karanganyar & 1200 & $7^{\circ} 42^{\prime} \mathrm{S} ; 111^{\circ} 80^{\prime} \mathrm{E}$ & February 2018 \\
\hline $\mathrm{J}$ & Batu & 875 & $7^{\circ} 42^{\prime} \mathrm{S} ; 112^{\circ} 42^{\prime} \mathrm{E}$ & February 2018 \\
\hline $\mathrm{K}$ & Mojokerto 2 & 700 & $7^{\circ} 40^{\prime} \mathrm{S} ; 112^{\circ} 36^{\prime} \mathrm{E}$ & May 2019 \\
\hline
\end{tabular}

*Metres above mean sea level
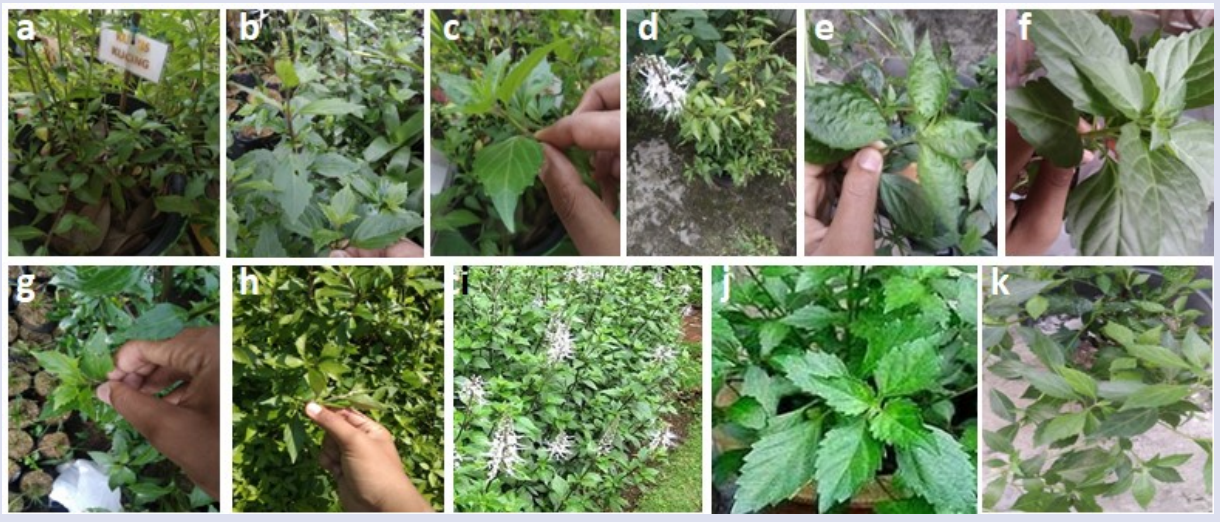

Figure 1: Orthosiphon stamineus from Lamongan (a), Pasuruan (b), Malang (c), Gresik (d), Surabaya (e), Sidoarjo (f), Jombang (g), Mojokerto 1 (h), Karanganyar (i), Batu (j), and Mojokerto 2 (k). 
TLC-Visualizer. Quantitative evaluation of digitized images was carried out with Camag VideoScan 1.02 software.

\section{Selection of the mobile phase}

Ten $\mathrm{ml}$ of each solvent i.e. diethyl ether, 2-propanol, ethanol, tetrahydrofuran, acetic acid, dichloromethane, ethyl acetate, dioxane, toluene, and chloroform were put into a twin-through chamber and saturated for 30 minutes. Five $\mu \mathrm{l}$ of OS leaves extract was applied on TLC plate. The plate was then developed with the migration distance of $80 \mathrm{~mm}$. After development, the plates were removed and dried at room temperature. In addition to the single mobile phase, the selection of mobile phase was also carried out using mixture of two or three solvents with various comparisons to obtain a chromatogram with the highest number and the best separations of zones.

\section{Stability of the chromatograms}

The stability of analytes in solution and on the plate was assessed by leaving the extract at room temperature and on the plate for 3 hours. As a standard, the new extract was prepared and applied just before the elution is started. The analytes were considered to be stable in the solution and on the plate before the chromatographic process if the difference of their Rf value is not more than 0.05 . Stability of the analytes during chromatography was evaluated by two-dimensional (2D) elution. The analytes were concluded to be stable during the chromatographic process if all zones located on a diagonal connecting the initial position of the application with the intersection of the two mobile phase fronts. Moreover, to investigate the stability of the chromatographic result, the sample was chromatographed according to the method and derivatized with anisaldehyde-sulfuric acid reagent. The chromatogram was evaluated using TLC-visualizer repeatedly after $5,10,30$, and 60 minutes. The chromatogram was concluded to be stable if there are no significant changes in Rf value. ${ }^{19}$

\section{Precision of the chromatograms}

Orthosiphon stamineus leaves were extracted in triplicate. Each extract was chromatographed three times on 3 different plates. Intraday precision was analyzed by calculating the $\mathrm{Rf}$ values of several prominent zones then calculating its mean and relative standard deviation. A reasonable acceptance criterion would be that $\mathrm{Rf}$ values of the same compounds do not vary more than 0.02 from plate to plate. To determine the interday precision, the extract was applied three times on 3 different plates and on 3 different days. Interday precision was acceptable if Rf values of the same substances vary not more than 0.05 between plates from different days. ${ }^{19}$

\section{TLC of samples from different origins}

OS leaves extracts from 11 different locations were chromatographed on a TLC plate. The TLC plate was then eluted as described before. TLC plate was subsequently illuminated under short-wave UV (254 $\mathrm{nm})$, long-wave UV (366 nm), and white light by using TLC-Visualizer. Videodensitogram of samples were then analyzed using chemometric method.

\section{Chemometric analysis}

Rf value, height, and area of each peak (compound) obtained from videodensitogram was tabulated and then analyzed using Principal Component Analysis (PCA). PCA is an exploratory data analysis. This method is based on the information available in the fingerprints only. PCA reduces the complexity of the multivariate data set by explaining the correlation amongst a large number of variables in terms of a smaller number of underlying factors (principal components or PCs) without losing much information. The projections of the $\mathrm{n}$ objects from the original data on PCs are called the scores plots, whereas the contribution of each original variable to the score is presented by its loading, which detects the variables responsible for the clustering ${ }^{15}$. PCA was carried out using Minitab v.16 (Minitab Inc., USA).

\section{RESULTS AND DISCUSSION}

\section{Selection of the mobile phase}

Methanol extracts of OS leaves collected from 11 origins are presented at Figure 2. All of extracts show dark green colour, except OS extract from Batu district (sample j). This is an initial indicator that sample from Batu may differ from the others. One of these extracts was then chosen for the mobile phase selection. At the first step, 10 single mobile phases were used and chloroform, dichloromethane, as well as ethyl acetate were the best mobile phase. These single mobile phases exhibited the most number and the best separation of zones on the TLC plate. These solvents were then mixed using simplex centroid with axial design. ${ }^{20}$ Ten types of combination in different ratio were deduced and $\mathrm{CHCL}_{3}$, DCM, EA (4:1:1) showed the optimum solvent system (Figure 3 ). However, the separation of zones with this solvent ratio was not so good, therefore modified ratios were applied i.e. 5:2:1 and 7:4:1. Finally, $\mathrm{CHCL}_{3}$, DCM, EA in the ratio of 7:4:1 was then selected as a solvent system for the development of OS TLC fingerprinting. It exhibited 11 zones after derivatized with anisaldehyde-sulfuric acid reagent under white light.

\section{Stability test}

The stability of the analytes before and during the chromatography process is important to be established due to off-line nature of TLC system. The stability of the analyte before chromatography was determined by developing two extracts prepared at different times. The $\mathrm{Rf}$ values of the prominent zone or marker $\left({ }^{*}\right.$, yellowish-blue) at tracks I and II were compared to those at tracks III and IV to evaluate the stability of the analytes on the plate, while the zones at tracks V and VI were compared to those at tracks III and IV to assess the stability of the analytes in the solution. ${ }^{19}$ The results showed that all tracks afforded the same pattern (Figure 4 ) and $\mathrm{Rf}$ value, with the $\Delta \mathrm{Rf}<0.05$ (Table 2). These indicated that the analytes remained stable for three hours before chromatography began, both on the plates and in the extract solution.

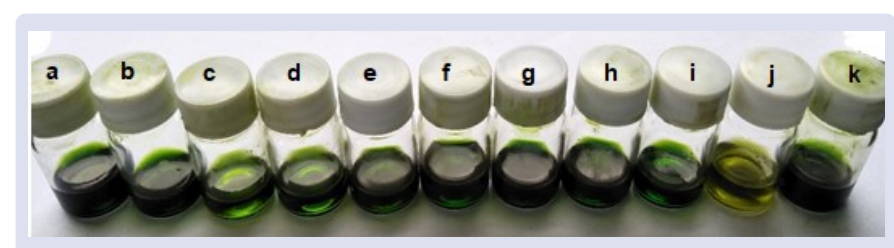

Figure 2: Orthosiphon stamineus leaves extracts from Lamongan (a), Pasuruan (b), Malang (c), Gresik (d), Surabaya (e), Sidoarjo (f), Jombang (g), Mojokerto 1 (h), Karanganyar (i), Batu (j), and Mojokerto 2 (k).

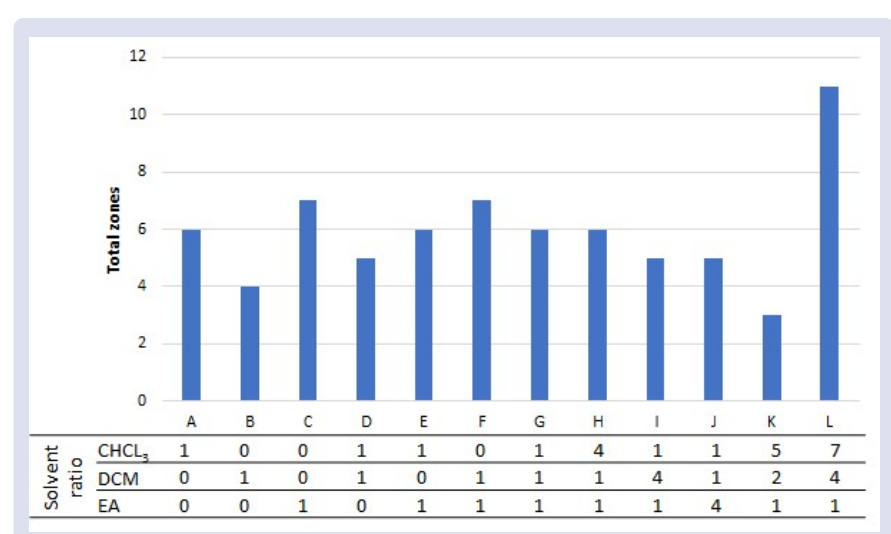

Figure 3: Total zones of OS leaves extract. Mobile phase (MP): $\mathrm{CHCL}_{3}, \mathrm{DCM}$, $E A$ in different ratios. Detection (D): anisaldehyde-sulfuric acid reagent, white light. 


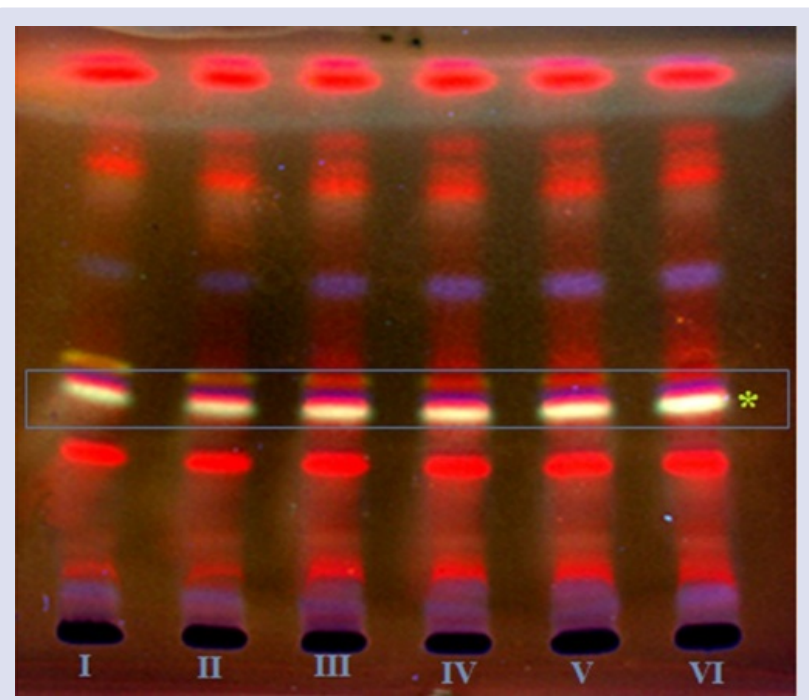

Figure 4: Stability of the analytes on plate and in solution. I, II: extracts on the plate for 3 hours; III, IV: extracts on the plate for less than 5 minutes; $\mathrm{V}$, VI: extracts in solution for 3 hours. $\mathrm{MP}$ : $\mathrm{CHCL}_{3^{\prime}}$ DCM, EA (7:4:1). D: anisaldehyde-sulfuric acid reagent, UV $366 \mathrm{~nm}$.

Table 2: Stability of analyte on the plate and in solution.

\begin{tabular}{ccccccc}
\hline $\begin{array}{c}\text { Marker } \\
(*)\end{array}$ & Track I & Track II & Track III & Track IV & Track V & Track VI \\
\hline \multirow{2}{*}{ Colour } & $\begin{array}{c}\text { Yellowish- } \\
\text { blue }\end{array}$ & bllowish- & Yellowish- & Yellowish- & Yellowish- & Yellowish- \\
Rf & 0.418 & 0.394 & 0.388 & 0.384 & 0.391 & 0.403 \\
$\Delta \mathrm{Rf}^{1}$ & 0.032 & 0.008 & 0 & 0 & 0.005 & 0.017 \\
\hline
\end{tabular}

${ }^{1}$ calculated to the marker compound at tracks III and IV

Two-dimensional (2D) development was carried out to determine the stability of the analytes during chromatography. A stable compounds will have the same Rf value in the first and second elution. ${ }^{19}$ Figure 5 exhibited that the analytes were stable during the chromatographic process indicated by a diagonal line on $2 \mathrm{D}$ chromatogram, including marker compound $\left(^{*}\right)$.

Stability of the chromatographic results was determined by observing the color of the zones for 60 minutes. Figure 6 and Table 3 showed that the number and color of the zones were stable for 60 minutes. Differences of $\mathrm{Rf}$ value for the marker zone was not more than 0.05 .

\section{Precision test}

Intraday precision test was conducted by chromatography of three OS leaves extracts prepared at the same time on one plate. Chromatography was replicated on 3 plates on the same day. Figure 7 and Table 4 show that the intraday precision of the method is acceptable since the $\Delta \mathrm{Rf}$ values of the marker zone ${ }^{*}$ ) from plate to plate is $0.02 .{ }^{19}$

The interday precision test was carried out similar to those of intraday precision, however the development of plates I, II, and III was conducted on 3 different days. Figure 8 and Table 5 exhibited that the interday precision of the method is acceptable because the difference of the $\mathrm{Rf}$ value of marker $\left.{ }^{*}\right)$ is $0.02 .{ }^{19}$

\section{TLC-fingerprints of OS leaves from different origins}

TLC profiles of OS leaves from 11 origins before and after derivatization are shown in Figure 9 and 10. Visually, sample 7 (Jombang) and 10 (Batu) showed significant differences compared to the others. Sample 7 has more zones and is more intensive compared to the others, while sample 10 is the opposite. This profile correlates with the colour of extract as presented at Figure 2.
TLC-fingerprint of samples after derivatization and visualized under UV $366 \mathrm{~nm}$ was then transferred into videodensitogram (Figure 11) to show their Rf value, height, and area. Total peak number of each sample varies between 27 and 34 peaks, all show major peak with Rf value 0.2 0.3 . This peak can be further studied and can be considered as marker compound for OS. Moreover, height and peak area of sample 7 is more prominent compared to the others. This can be an initial indicator that the quality of sample 7 is better than the others. To compare the quality of samples more objectively, chemometric analysis was then performed on these TLC-fingerprints.

\section{Principal component analysis (PCA)}

Videodensitogram of OS leaves extracts from 11 different origins were analyzed with chemometric using PCA method. The height and area of each peak detected on the videodensitogram were then tabulated based on the origin of the sample (table is not shown). PCA with full cross validation was applied to the data set of the 11 fingerprints of OS from 11 origins, 3 replications respectively. Analysis was conducted

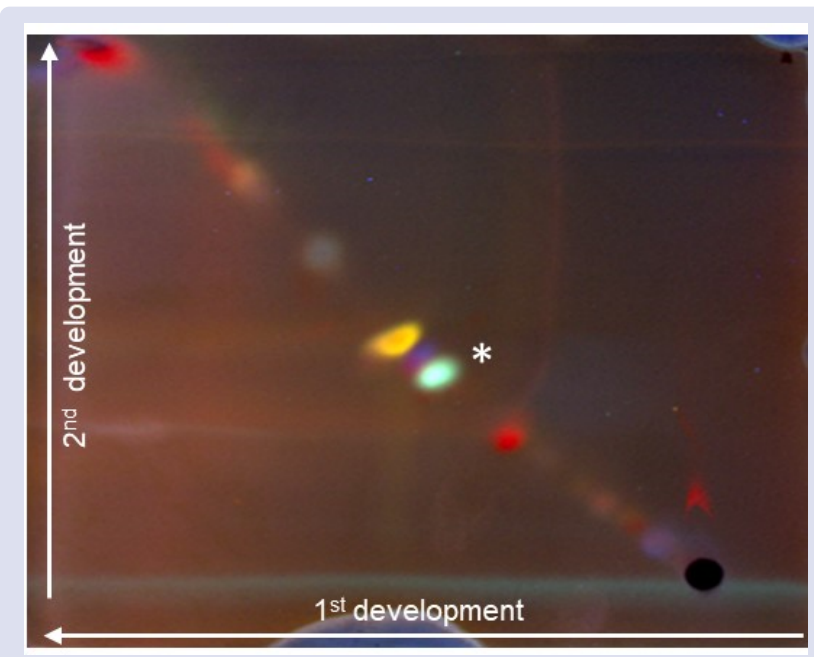

Figure 5: Stability of the analytes during chromatography. MP. $\mathrm{CHCL}_{3^{\prime}}$ DCM, EA (7:4:1). D: anisaldehyde-sulfuric acid reagent, UV 366 $\mathrm{nm}$.

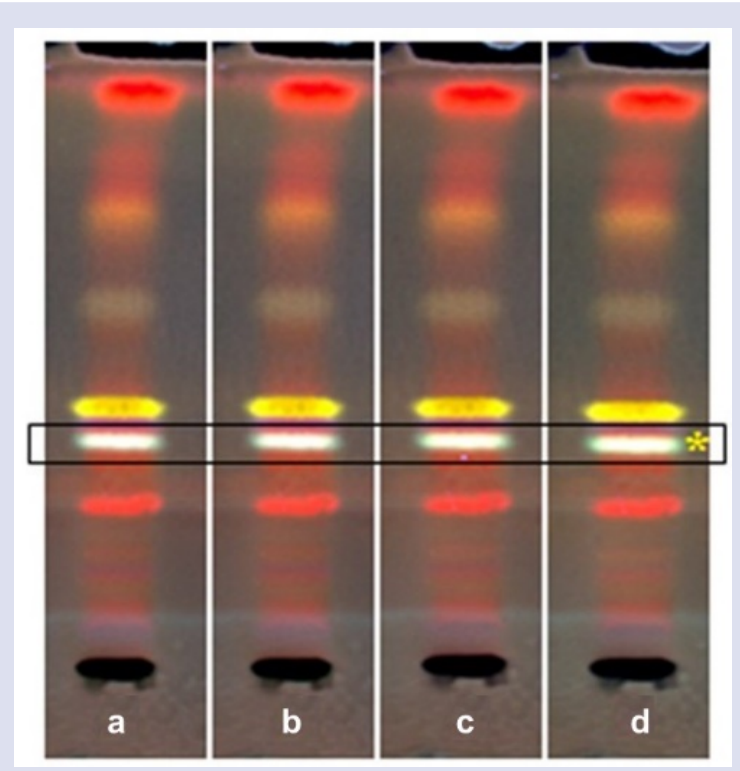

Figure 6: Stability of the chromatographic result after 5 (a), 10 (b), 30 (c), and 60 minutes (d). MP: $\mathrm{CHCL}_{3}$, DCM, EA (7:4:1). D: anisaldehyde-sulfuric acid reagent, UV $366 \mathrm{~nm}$. 
Table 3: Stability of the chromatographic result.

\begin{tabular}{ccccc}
\hline Marker $(*)$ & Track a & Track b & Track c & Track d \\
\hline Colour & Yellowish-blue & Yellowish-blue & Yellowish-blue & Yellowish-blue \\
Rf & 0.367 & 0.366 & 0.376 & 0.378 \\
$\Delta \mathrm{Rf}^{1}$ & 0 & 0.001 & 0.009 & 0.011 \\
\hline
\end{tabular}

${ }^{1}$ calculated to the marker compound at track a

\section{Table 4: Intraday precision test.}

\begin{tabular}{|c|c|c|c|c|c|c|c|c|c|}
\hline \multirow{2}{*}{ Marker (*) } & \multicolumn{9}{|c|}{ Track } \\
\hline & I.1 & 1.2 & 1.3 & II.1 & II. 2 & II. 3 & III.1 & III.2 & III.3 \\
\hline Colour & \multicolumn{3}{|c|}{ Yellowish-blue } & \multicolumn{3}{|c|}{ Yellowish-blue } & \multicolumn{3}{|c|}{ Yellowish-blue } \\
\hline $\mathrm{Rf}$ & 0.404 & 0.388 & 0.388 & 0.431 & 0.409 & 0.406 & 0.415 & 0.402 & 0.393 \\
\hline Mean of Rf & & 0.39 & & & 0.41 & & & 0.40 & \\
\hline$\Delta \mathrm{Rf}$ & & & & & 0.02 & & & & \\
\hline
\end{tabular}

\section{Table 5: Interday precision test.}

\begin{tabular}{cccccccccc}
\hline \multirow{2}{*}{ Marker $\left.*^{*}\right)$} & \multicolumn{8}{c}{ Track } \\
\cline { 2 - 10 } & I.1 & I.2 & I.3 & II.1 & II.2 & II.3 & III.1 & III.2 & III.3 \\
\hline Colour & \multicolumn{2}{c}{ Yellowish-blue } & \multicolumn{2}{c}{ Yellowish-blue } & \multicolumn{2}{c}{ Yellowish-blue } \\
Rf & 0.404 & 0.388 & 0.388 & 0.431 & 0.409 & 0.406 & 0.420 & 0.377 & 0.367 \\
Mean Rf & & 0.39 & & & 0.41 & & & 0.38 & \\
$\Delta$ Rf & & & 0.02 & & & \\
\hline
\end{tabular}

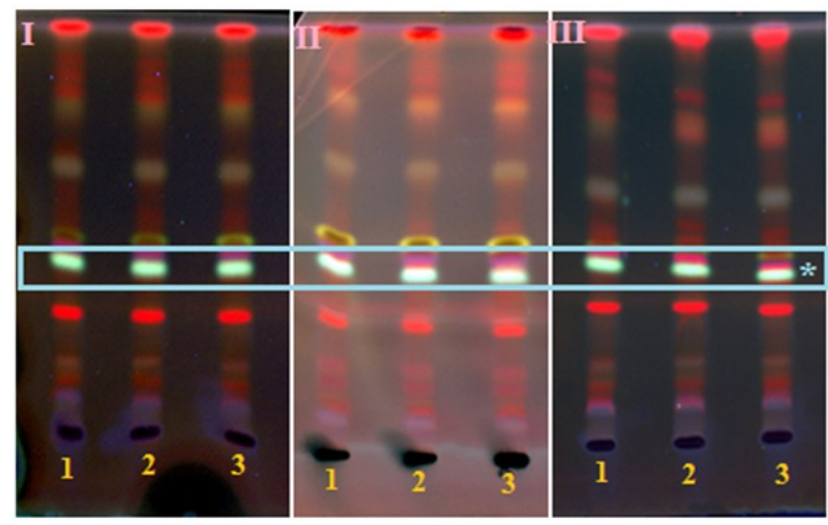

Figure 7: Intraday precision test. 1, 2, 3 are OS leaves extracts prepared separately, while I, II, III show the different plates. MP: $\mathrm{CHCL}_{3}, \mathrm{DCM}$, EA (7:4:1). D: anisaldehyde-sulfuric acid reagent, UV $366 \mathrm{~nm}$.

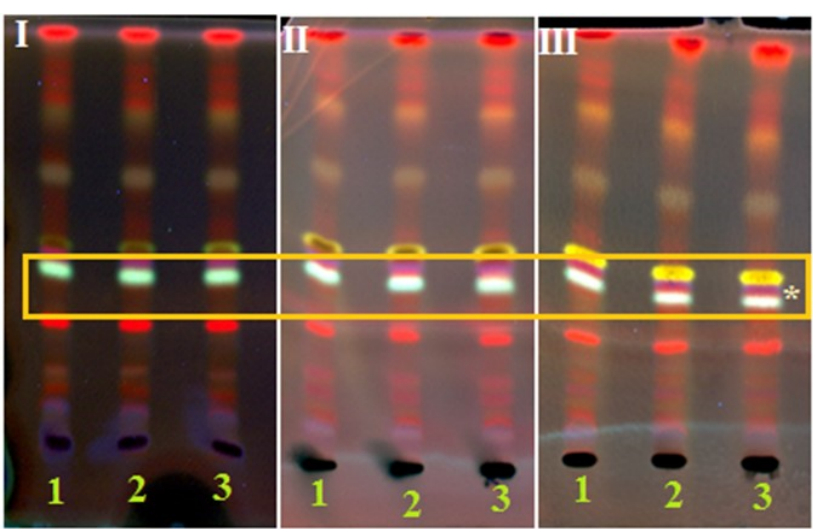

Figure 8: Interday precision test. 1, 2, 3 are OS leaves extracts prepared separately, while I, II, III show the plates developed in 3 different days. MP: $\mathrm{CHCL}_{3}, \mathrm{DCM}, \mathrm{EA}$ (7:4:1). D: anisaldehyde-sulfuric acid reagent, UV $366 \mathrm{~nm}$.

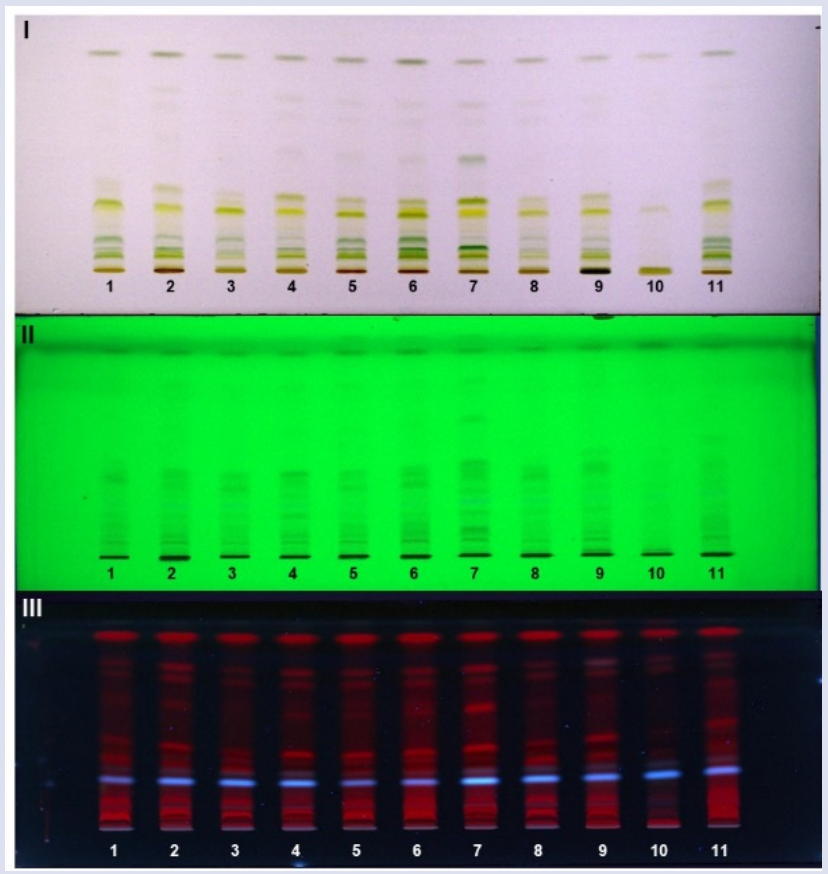

Figure 9: TLC-fingerprint OS leaves from Lamongan (1), Pasuruan (2), Malang (3), Gresik (4), Surabaya (5), Sidoarjo (6), Jombang (7), Mojokerto (8), Karanganyar (9), Batu (10), and Mojokerto (11). MP: $\mathrm{CHCL}_{3}$, DCM, EA (7:4:1). D: none, white light (I), UV $254 \mathrm{~nm}$ (II), UV 366 $\mathrm{nm}$ (III).

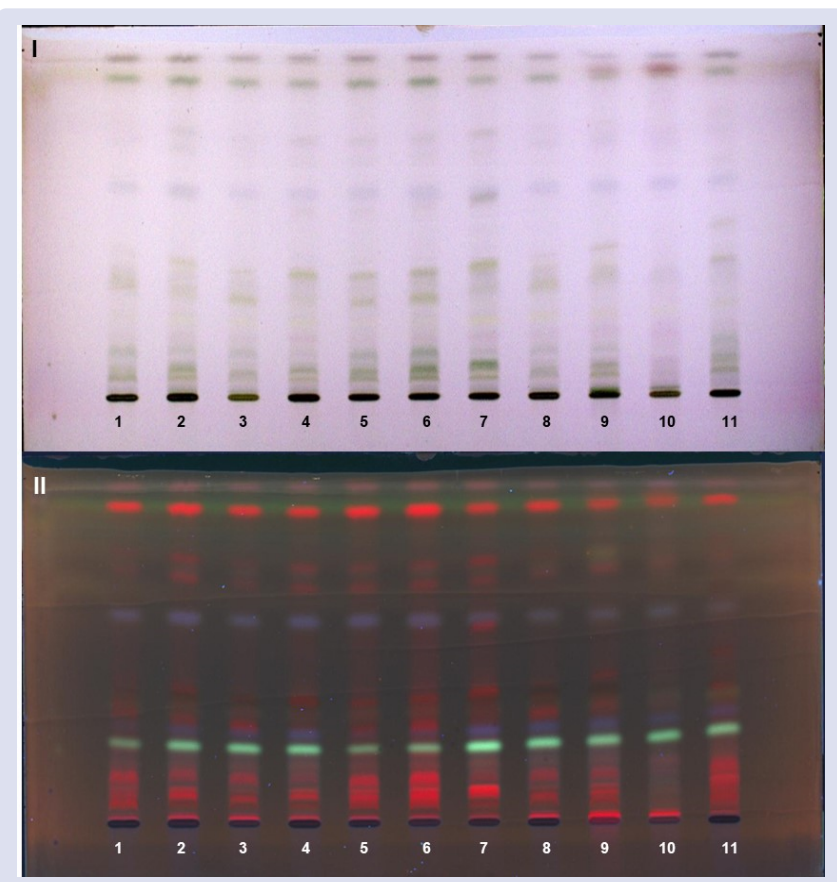

Figure 10: TLC-fingerprint of OS leaves from Lamongan (1), Pasuruan (2), Malang (3), Gresik (4), Surabaya (5), Sidoarjo (6), Jombang (7), Mojokerto (8), Karanganyar (9), Batu (10), and Mojokerto (11). MP: $\mathrm{CHCL}_{3}, \mathrm{DCM}, \mathrm{EA}(7: 4: 1)$. D: anisaldehyde-sulfuric acid reagent, white light (I), UV $366 \mathrm{~nm}$ (II). 
on the peak height and area of the full fingerprints without any preprocessing. The score plot of the first two PC (Figure 12) clearly distinguished 3 clusters of samples. The first cluster consists of OS from Mojokerto 1, Mojokerto 2, Malang, Jombang, and Sidoarjo. OS from Gresik, Pasuruan, Lamongan, Surabaya, and Karang Anyar gathered as second cluster, whereas third cluster consists of a sample from Batu. Samples in the cluster 1 show that the compounds with Rf value 0.20.3 are higher than those in clusters 2 and 3 . However, these results indicate that the clustering of OS samples is not directly related to the height of the original location. Other factors such as soil type, rainfall, lighting, fertilizing, etc. are predicted to be responsible for the samples grouping. ${ }^{21}$

To estimate which compounds are responsible for the grouping, PCA was conducted by projecting each origin variable called as loading plot. The loading plot of the first PC (Figure 13) showed that compounds with the Rf values of $0.0-0.1,0.1-0.2,0.2-0.3$, and $0.9-1.0$ are the most important compounds for clustering of samples.

Previous studies have been carried out to classify OS from different geographical origin. They involved both chromatography (HPLC, GC)

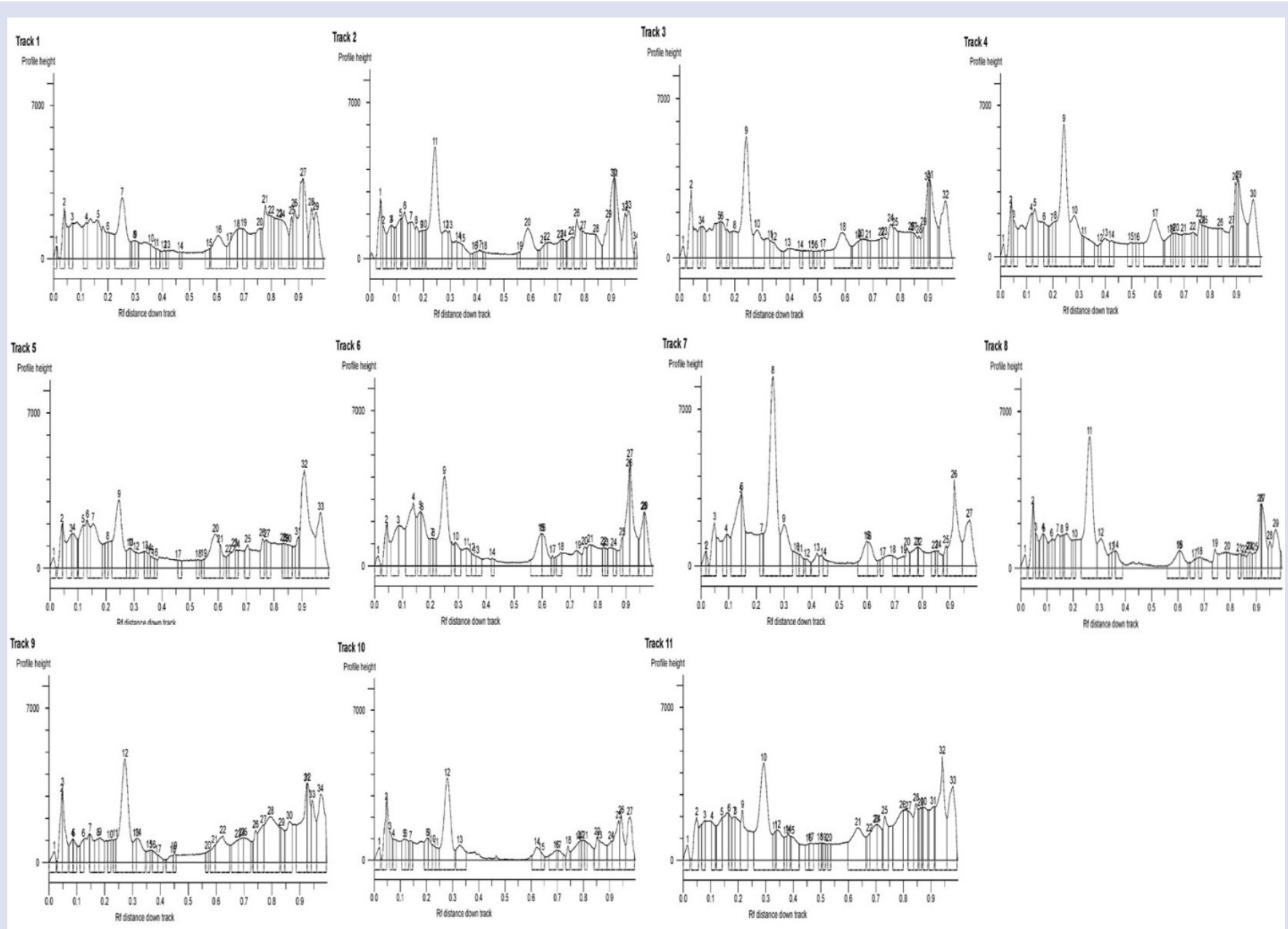

Figure 11: Videodensitogram of OS leaves, track 1-11 represent samples from Lamongan, Pasuruan, Malang, Gresik, Surabaya, Sidoarjo, Jombang, Mojokerto, Karanganyar, Batu, and Mojokerto, respectively.
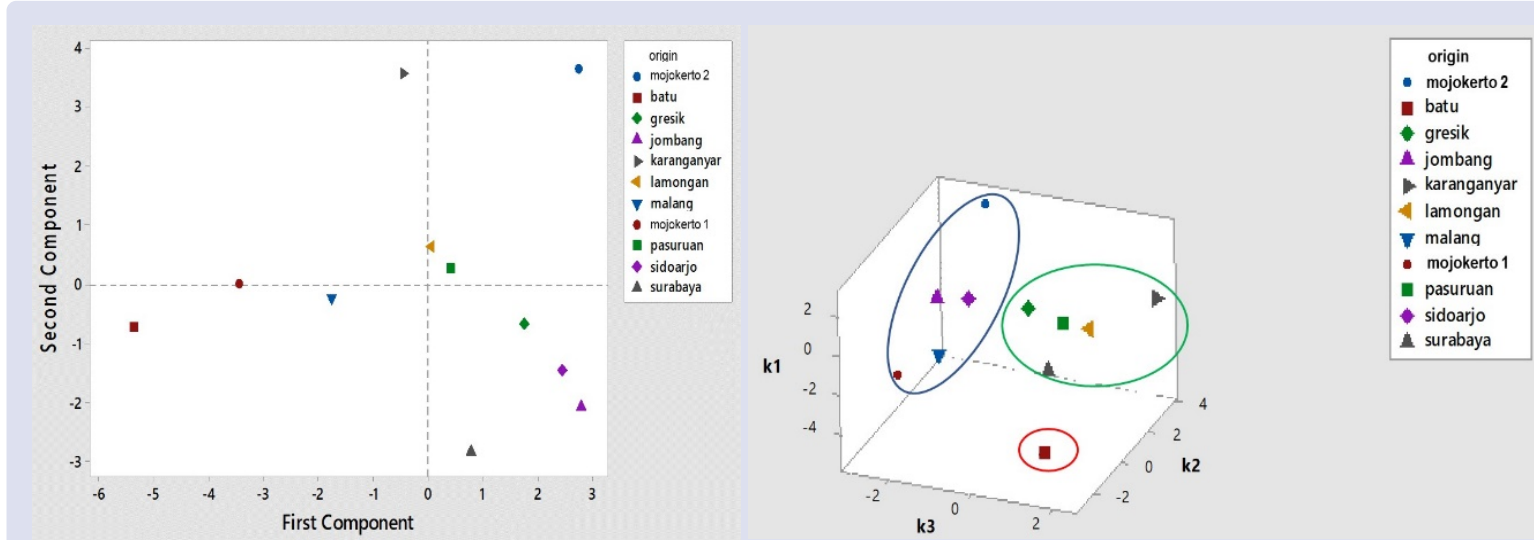

Figure 12: PCA score plot of OS from different origins on the first two principal components. 


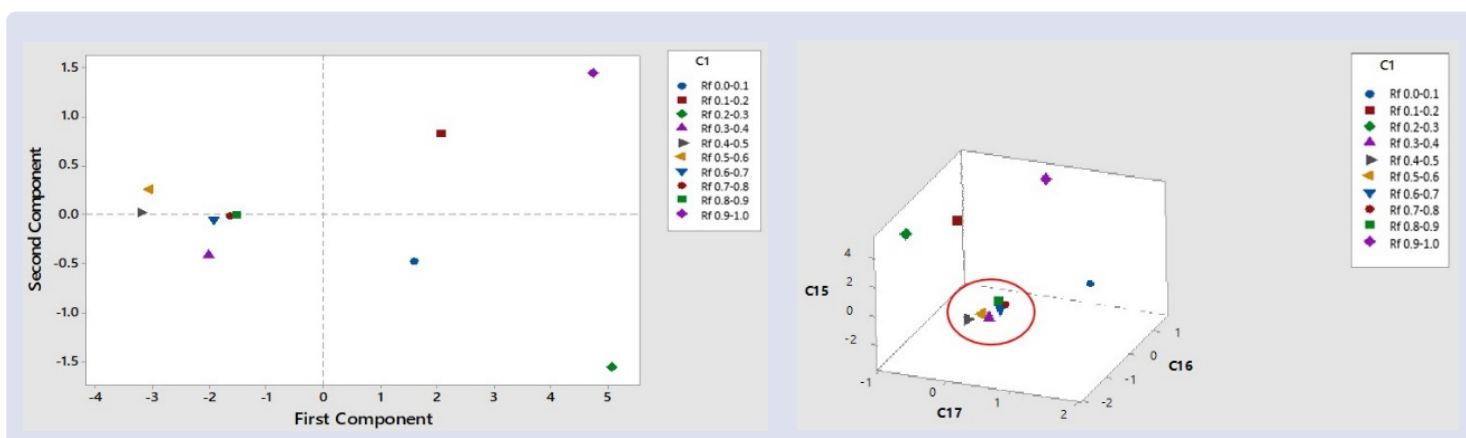

Figure 13: PCA loading plot of OS from different origins on the first two principal components.

as well as spectroscopy (FTIR) method coupled with chemometrics analysis. ${ }^{10-12}$ Our finding suggested that TLC fingerprint coupled with chemometrics analysis is a good alternative method to HPLC, GC, and FTIR for quality control of OS as well as the other crude drugs. In addition to its simplicity and low cost, by using TLC we can simultaneously analysis up to 20 samples under identical conditions.

\section{CONCLUSION}

TLC-fingerprint combined with the PCA was able to discriminate among the leaves of Orthosiphon stamineus originated from various locations. Compounds with the $\mathrm{Rf}$ values $0.0-0.1,0.1-0.2,0.2-0.3$, and 0.9-1.0 are the most important compounds for the clustering of samples. TLC-fingerprints analyzed with chemometrics is powerful method to evaluate the quality of Orthosiphon stamineus.

\section{ACKNOWLEDGEMENTS}

The authors are thankful to Ministry of Research, Technology, and Higher Education of the Republic of Indonesia for financing this research under Fundamental Research Scheme with the contract number: 004/SP2H/LT/MULTI/L7/2019. This work also supported by University of Surabaya under Competitive Research Scheme with the contract number: 017/SP-Lit/LPPM-01/Int/FF/III/2019.

\section{REFERENCES}

1. Adnyana IK, Setiawan F, Insanu M. From ethnopharmacology to clinical study of Orthosiphon stamineus Benth. studies. 2013;5(3):66-73.

2. Akowuah G, Zhari I, Norhayati I, Sadikun A. Radical scavenging activity of methanol leaf extracts of orthosiphon stamineus. Pharmaceutical Biology. 2005;42(8):629-35.

3. Ho CH, Noryati I, Sulaiman SF, Rosma A. In vitro antibacterial and antioxidant activities of Orthosiphon stamineus Benth. extracts against food-borne bacteria. Food Chemistry. 2010;122(4):1168-72.

4. Mohamed EAH, Siddiqui MJA, Ang LF, Sadikun A, Chan SH, Tan SC, et al. Potent $\alpha$-glucosidase and $\alpha$-amylase inhibitory activities of standardized $50 \%$ ethanolic extracts and sinensetin from Orthosiphon stamineus Benth as anti-diabetic mechanism. BMC Complementary and Alternative Medicine. 2012;12(1): 176

5. Alshawsh MA, Abdulla MA, Ismail S, Amin ZA, Qader SW, Hadi HA, et al. Free radical scavenging, antimicrobial and immunomodulatory activities of Orthosiphon stamineus. Molecules. 2012;17(5):5385-95.

6. Siddiqui MJA, Ismail Z. Simultaneous analysis of bioactive markers from Orthosiphon stamineus Benth leaves extracts by reverse phase high performance liquid chromatography. Tropical Journal of Pharmaceutical Research. 2011;10(1):97-103.
7. Man S, Kiong LS, Ab'lah NA, Abdullah Z. Differentiation of the white and purple flower forms of orthosiphon aristatus (Blume) Miq. BY 1D and 2D correlation IR spectroscopy. Jurnal Teknologi. 2015;77(3):81-6.

8. Ameer OZ, Salman IM, Asmawi MZ, Ibraheem ZO, Yam MF. Orthosiphon stamineus: traditional uses, phytochemistry, pharmacology, and toxicology Journal of Medicinal Food. 2012;15(8):678-90.

9. Chew K, Khoo M, Ng S, Thoo Y, Aida WW, Ho C. Effect of ethanol concentration, extraction time and extraction temperature on the recovery of phenolic compounds and antioxidant capacity of Orthosiphon stamineus extracts. International Food Research Journal. 2011;18(4):1427-35.

10. Rafi M, Purwakusumah ED, Ridwan T, Barus B, Sutandi A, Darusman LK Geographical classification of Java tea (Orthosiphon stamineus) from Java Island by FTIR spectrocopy combined with canonical variate analysis. J Sains Matematika. 2015;23:25-31.

11. Saidan NH, Hamil MSR, Memon AH, Abdelbari MM, Hamdan MR, Mohd KS, et al. Selected metabolites profiling of Orthosiphon stamineus Benth leaves extracts combined with chemometrics analysis and correlation with biological activities. BMC Complementary and Alternative Medicine. 2015;15(1):350-62.

12. Sim C, Ahmad M, Ismail Z, Othman A, Noor N, Zaihidee E. Chemometric classification of herb-Orthosiphon stamineus according to its geographical origin using virtual chemical sensor based upon fast GC. Sensors. 2003;3(10):458-71.

13. Akowuah G, Zhari I, Sadikun A, Norhayati I. HPTLC Densitometric Analysis of Orthosiphon stamineus. Leaf Extracts and Inhibitory Effect on Xanthine Oxidase Activity. Pharmaceutical Biology. 2006;44(1):65-70.

14. Hashim S, Beh H, Hamil M, Ismail Z, Majid A. High-performance thinlayer chromatography method development, validation, and simultaneous quantification of four compounds identified in standardized extracts of Orthosiphon stamineus. Gad HA, El-Ahmady SH, Abou-Shoer MI, Al-Azizi MM Application of chemometrics in authentication of herbal medicines: a review. Phytochem Anal. 2013;24(1):1-24.

15. Tistaert C, Dejaegher B, Heyden YV. Chromatographic separation techniques and data handling methods for herbal fingerprints: a review. Analytica Chimica Acta. 2011;690(2):148-61.

16. Komsta $Ł$. Chemometrics in fingerprinting by means of thin layer chromatography. Chromatography Research International. 2011;2012.

17. Bansal A, Chhabra V, Rawal RK, Sharma S. Chemometrics: a new scenario in herbal drug standardization. Journal of Pharmaceutical Analysis. 2014;4(4):22333.

18. Reich E, Schibli A. High-performance thin-layer chromatography for the analysis of medicinal plants. New York: Thieme; 2007.

19. Brereton RG. Chemometrics: data analysis for the laboratory and chemical plant. West Sussex: John Wiley \& Sons; 2003.

20. Kartini, Azminah. Chromatographic fingerprinting and clustering of Plantago major L. from different areas in Indonesia Asian Journal of Pharmaceutical and Clinical Research. 2012;5(4):191-5. 


\section{GRAPHICAL ABSTRACT}
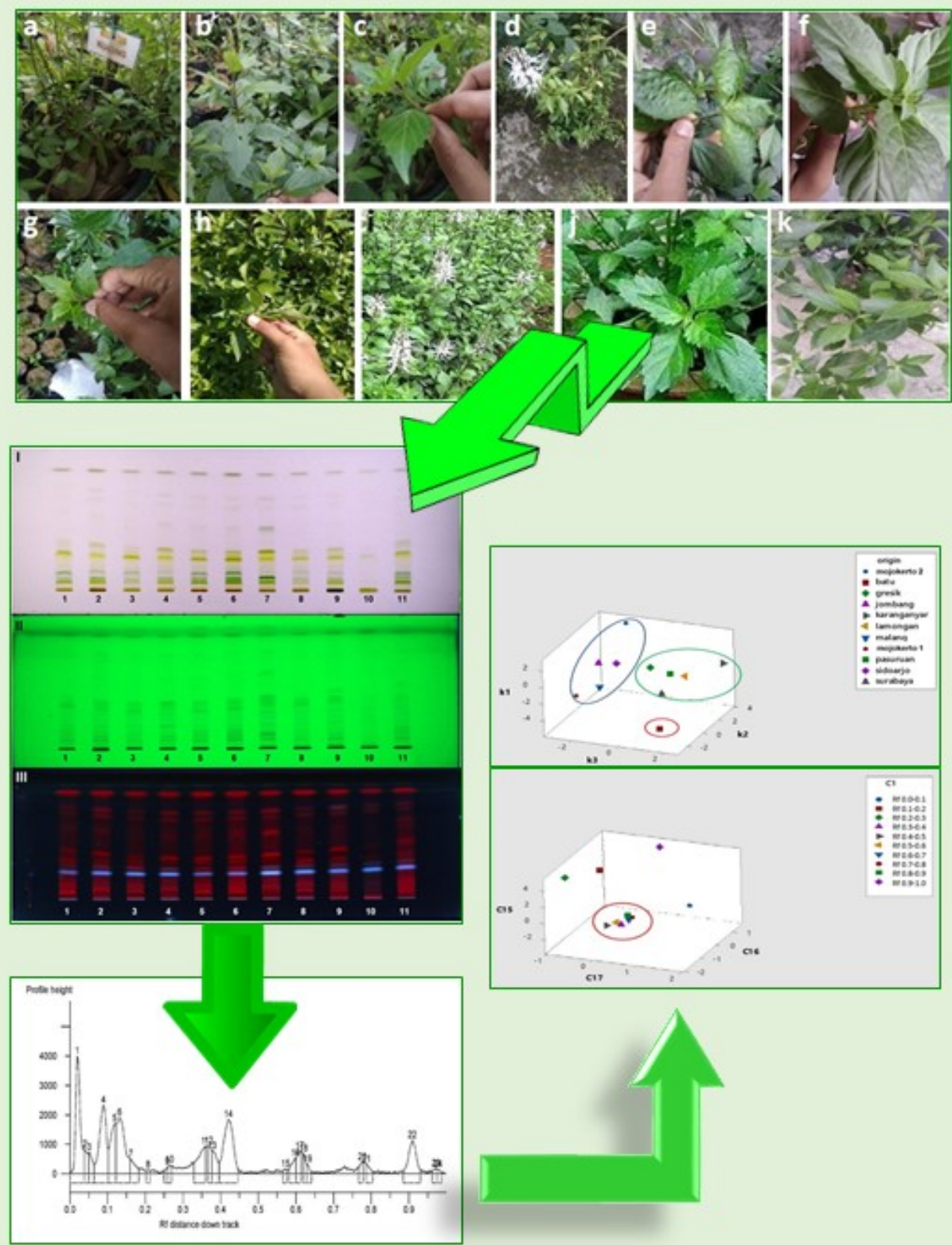

\section{ABOUT AUTHORS}

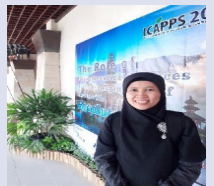

Kartini, Ph.D. is an Associate Professor in the Department of Pharmaceutical Biology, Faculty of Pharmacy, University of Surabaya, Indonesia. She has completed her Ph.D. in Phytopharmaceutical Sciences from Faculty of Graduate Studies Mahidol University, Thailand. She is currently the Director of Center for Traditional Medicine Information \& Development, Faculty of Pharmacy, University of Surabaya. She works on standardization of herbal medicines and its application as wound healing, anticancer, and immunomodulator.

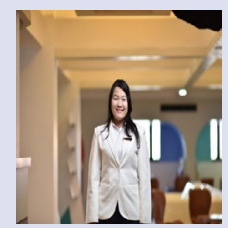

Ervina Rustiana Dewi is a pharmacist who graduated from Faculty of Pharmacy, University of Surabaya, Indonesia. Her research focused on pharmacognosy study and standardization of Orthosiphon stamineus. 


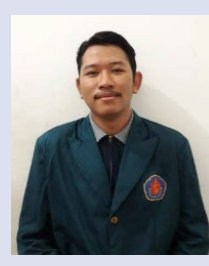

Fandi Achmad is a pharmacist who graduated from Faculty of Pharmacy, University of Surabaya, Indonesia. $\mathrm{He}$ is interested on research focusing on phytochemistry and quality assurance of Orthosiphon stamineus.

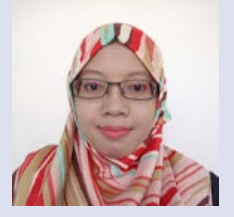

Nikmatul Ikhrom Eka Jayani, M.Pharm.-Clin. is a lecturer of Pharmaceutical Biology Department, Faculty of Pharmacy, University of Surabaya, Indonesia. She teaches some subjects, including Pharmacognosy and Indonesian Indigenous Herbal Medicine. She focuses her research on standardization of herbal medicine and its activity as antidiabetes as well as its application in community setting.

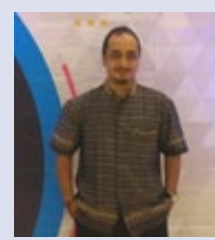

M. Arbi Hadiyat, M.Sc. is a lecturer of Industrial Engineering Department, Faculty of Engineering, University of Surabaya, Indonesia. Some courses have been taught by him, such as Industrial Statistics, Design of Experiment, and Quality Engineering. Currently, he is working on some researches in quality and process design optimization, machine learning in industry, and customer satisfaction mathematical model.

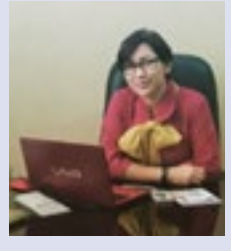

Christina Avanti, Ph.D. is an Associate Professor, Vice Rector for Student Affairs and Alumni, Former Dean of Faculty of Pharmacy University of Surabaya, Indonesia. PhD graduated in Pharmacy at the Department of Pharmaceutical Technology and Biopharmacy University of Groningen. She is currently working in several projects developing techniques to improve bioavailability and stability of lipophilic pharmaceuticals and develop modified delivery system of Indonesian medicinal plants.

Cite this article: Kartini K, Dewi ER, Achmad F, Jayani NIE, Hadiyat MA, Avanti C. Thin Layer Chromatography Fingerprinting and Clustering of Orthosiphon stamineus Benth. from Different Origins. Pharmacog J. 2020;12(1):79-87. 